\title{
Antidiabetic Flavonoids from Fruits of Morus alba Promoting Insulin-Stimulated Glucose Uptake via Akt and AMP-Activated Protein Kinase Activation in 3T3-L1 Adipocytes
}

\author{
Sung Ho Lim ${ }^{1,+}$, Jae Sik Yu ${ }^{2,+}$, Ho Seon Lee ${ }^{3}$, Chang-Ik Choi ${ }^{3, *}$ and Ki Hyun Kim ${ }^{2, *}$ (D) \\ 1 BK21 FOUR Team and Integrated Research Institute for Drug Development, College of Pharmacy, Dongguk \\ University-Seoul, Goyang 10326, Korea; 93sho617@naver.com \\ 2 School of Pharmacy, Sungkyunkwan University, Suwon 16419, Korea; jsyu@bu.edu \\ 3 Integrated Research Institute for Drug Development, College of Pharmacy, Dongguk University-Seoul, \\ Goyang 10326, Korea; ghtjsrhtn@naver.com \\ * Correspondence: cichoi@dongguk.edu (C.-I.C.); khkim83@skku.edu (K.H.K.); \\ Tel.: +82-31-961-5230 (C.-I.C.); +82-31-290-7700 (K.H.K.) \\ + These authors contributed equally to this study.
}

check for updates

Citation: Lim, S.H.; Yu, J.S.; Lee, H.S.; Choi, C.-I.; Kim, K.H. Antidiabetic Flavonoids from Fruits of Morus alba Promoting Insulin-Stimulated Glucose Uptake via Akt and AMP-Activated Protein Kinase Activation in 3T3-L1 Adipocytes. Pharmaceutics 2021, 13, 526. https://doi.org/10.3390/ pharmaceutics 13040526

Academic Editors: Javier Garcia-Pardo, Maria Camilla Bergonzi and Charles M. Heard

Received: 26 February 2021

Accepted: 5 April 2021

Published: 9 April 2021

Publisher's Note: MDPI stays neutral with regard to jurisdictional claims in published maps and institutional affiliations.

Copyright: () 2021 by the authors. Licensee MDPI, Basel, Switzerland. This article is an open access article distributed under the terms and conditions of the Creative Commons Attribution (CC BY) license (https:// creativecommons.org/licenses/by/ $4.0 /)$.

\begin{abstract}
Morus alba (Moraceae), known as white mulberry, has been used to treat fever, protect against liver damage, improve eyesight, and lower blood sugar levels in traditional oriental medicine. Few studies have been conducted on the antidiabetic compounds identified from M. alba and their underlying mechanisms of action. Consequently, in this study, the fruits of M. alba were investigated for potential antidiabetic natural products using 3T3-L1 adipocytes. Phytochemical analysis of the ethanolic extract of M. alba fruits, followed by high-performance liquid chromatography (HPLC), purification led to the isolation of two main compounds: rutin and quercetin-3-O- $\beta$-D-glucoside (Q3G). Long-term use of available drugs for treating type 2 diabetes ((T2D) is often accompanied by undesirable side effects, which have generated increased interest in the development of more effective and safer antidiabetic agents. Examination of the isolated compounds, rutin and Q3G, for antidiabetic or anti-obesity properties or both in 3T3-L1 adipocytes demonstrated that they both improved glucose uptake via Akt-mediated insulin signaling pathway or AMP-activated protein kinase (AMPK) activation in 3T3-L1 adipocytes. The compounds also showed a positive effect on lipid accumulation in adipocytes, suggesting that glucose uptake occurred through activation of the Akt and AMPK signaling pathway without inducing adipogenesis. Taken together, our findings suggest that rutin and Q3G in $M$. alba fruits have the potential to induce fewer side effects such as weight gain, and these active compounds could be potential therapeutic candidates for the management of T2D.
\end{abstract}

Keywords: type 2 diabetes; Morus alba; rutin; quercetin-3-O- $\beta$-D-glucoside; glucose uptake; lipid accumulation; 3T3-L1 adipocyte

\section{Introduction}

Type 2 diabetes (T2D) is a metabolic disorder that affected an estimated $2.8 \%$ of the world population in 2000, and this incidence is expected to rise to $4.4 \%$ by 2030 [1]. T2D affects metabolic organs, such as the muscle, liver, and adipose tissue, and arises from a defect in insulin usage. Hyperglycemia is a clinical marker of T2D, along with body and organ weight gain and insulin resistance. In particular, insulin resistance, which is a specific feature of T2D, often causes elevated blood glucose accompanied by increased blood pressure and lipid levels. This can lead to the development or exacerbation of chronic diseases such as obesity, hypertension, atherosclerosis, liver failure, and cancer. In this regard, enhancing glucose uptake to organs and tissues in the body is one of the important strategies for maintaining appropriate blood glucose levels in T2D patients. 
The maintenance of glucose homeostasis is essential for glucose uptake in insulinresponsive tissues such as skeletal muscles and adipose tissues in the human body. It is mediated by some members of a family of glucose transporters (GLUTs) [2], which have different substrate affinities, tissue-specific expression, and regulatory processes. GLUT1 and GLUT4 are two major glucose transporter isoforms expressed in adipose tissue, and many investigations have shown that they play a pivotal role in peripheral glucose regulation [2]. GLUT1 is a constitutive glucose transporter mainly located in plasma membranes and intracellular membranes, whereas the expression of GLUT4 is dependent on the amount of insulin and it is sequestered in intracellular vesicles under insulin insufficiency [3,4]. The phosphatidylinositol $3^{\prime}$ kinase (PI3K)/Akt and AMP-activated protein kinase (AMPK) pathways in adipocytes trigger GLUT4 translocation to the plasma membrane by insulin $[3,5]$. In several studies, overexpression of GLUT1, GLUT4, or both was found to cause hypoglycemia, whereas downregulation of GLUT4 led to insulin resistance [4]. It is known that increased expression and plasma membrane translocation of GLUT1 and GLUT4 improve glucose transport and utilization, thereby lowering blood glucose levels [6]. Glucose transferred to cells is metabolized or converted into its storage form, glycogen. Therefore, simultaneously enhancing glucose uptake and glycogen synthesis is considered the most beneficial therapeutic approach to overcome insulin resistance in T2D patients [7-9]. After binding to its cognate receptor, insulin activates the intrinsic protein tyrosine kinase activity and induces phosphorylation of tyrosine residues [10]. These activated receptors recruit and phosphorylate substrate molecules. Insulin receptor substrate (IRS) 1 and IRS2 are adapter molecules that play a central role in the coupling of PI3K/Akt and mitogen-activated protein kinase (MAPK) downstream kinases [11]. Tyrosine-phosphorylated IRS1/2 recruits the heterodimeric p85/p110 PI3K at the plasma membrane, where it produces the lipid second messenger phosphatidylinositol $(3,4,5)$ trisphosphate (PIP3), which in turn activates the serine/threonine phosphorylation cascade of PH domain-containing proteins [12]. PIP3 targets include phosphoinositide-dependent protein kinase 1 (PDK1), serine/threonine protein kinase $\mathrm{B}$ (PKB), also known as Akt, and atypical protein kinase $C \zeta$ and $\lambda$ isoforms $[13,14]$. Akt plays an important role in multiple cellular processes associated with cell growth, survival, proliferation, and metabolism [15]. Akt also plays a key role in insulin-stimulated glucose uptake in the muscle and adipose tissue. In contrast, it inhibits glucose release in hepatocytes [16]. Glucose uptake in peripheral tissues via $\mathrm{Akt} / \mathrm{PKB}$ is mediated by the translocation of GLUTs to the cell membrane by the effect of insulin, which facilitates glucose uptake.

AMPK is a nutrient-sensing serine/threonine kinase that is activated when the cellular energy level is low (i.e., high intracellular AMP:ATP ratio) and regulates energy homeostasis in the body. Activated AMPK subsequently induces downstream signals and restores energy to normal levels by stimulating ATP generation, such as fatty acid oxidation, and inhibiting ATP-consuming processes (e.g., triglycerides and protein synthesis) [17]. Thus, advantageous effects on metabolic disorders, such as T2D and obesity, play a central role in AMPK activation. Some antidiabetic drugs such as metformin and thiazolidinediones (TZDs) activate the AMPK signaling pathway [18]. In addition, AMPK activation enhances GLUT4 translocation into the plasma membrane of 3T3-L1 adipocytes [19].

Over the past few decades, the number of obese patients has increased rapidly, making it one of the most serious public health problems worldwide [20]. Obesity is closely related to insulin resistance in T2D patients, since both disorders involve dysfunction of endocrine, inflammatory, neuronal, and cellular intrinsic pathways [21]. Therefore, obesity-associated insulin resistance is considered a major risk factor for T2D [22]. The well-known link between obesity and insulin resistance in T2D is adipocyte dysregulation [23]. Hyperplasia and hypertrophy of adipose tissues are regulated by the capacity for lipid storage in adipocytes [24]. When the storage capacity reaches a threshold level in adipose tissues, excess fat is redistributed to other organs such as the liver, pancreas, or muscles, causing insulin resistance and toxic reactions. Abnormal fat accumulation in adipose tissue alters 
the expression of several inflammatory factors or adipokines, some of which also affect the insulin sensitivity in other metabolic organs [25].

Hypoglycemic agents with various mechanisms, including TZDs, sulfonylureas, and biguanides, are currently on the market to control blood glucose levels and prevent longterm complications in T2D patients. However, due to the potential for drug-induced side effects, such as hypoglycemic episodes, gastrointestinal disorders, weight gain, lactic acidosis, and low-density lipoprotein (LDL) cholesterol elevation, there is an increasing demand for the discovery of novel, naturally derived substances that are safe and pharmacologically effective [26].

As part of an ongoing research project to discover bioactive natural products [27-31], we investigated candidate phytochemicals from the extract of fruits of Morus alba L. to explore the antidiabetic or anti-obesity potential by using 3T3-L1 adipocytes. M. alba, also known as white mulberry or "sang shu," is a perennial plant belonging to the family Moraceae. This plant is native to China and is also widely cultivated in China, Japan, and Korea as an important food source for silkworms [32,33]. This plant grows numerous fruits with a sweet flavor, which are popularly consumed in various forms, including tea, beverages, and desserts, worldwide. Traditionally, the leaves, fruits, and bark of this plant have long been used to treat fever, protect against liver damage, improve eyesight, strengthen joints, facilitate the discharge of urine, and lower blood pressure [34]. Interestingly, in Korea and Japan, patients with diabetes consume mulberry leaves as an anti-hyperglycemic supplement [35], and the leaves are known to be effective against high blood pressure and hangover from alcohol and in lowering blood sugar levels related to diabetes [36]. Previous biological studies of $M$. alba have reported that its extracts exhibit diverse therapeutic properties, including antioxidant, antimicrobial, skin-whitening, cytotoxicity, anti-inflammatory, anti-hyperlipidemic, hepatoprotective, antidiabetic, and anti-obesity effects [37,38]. In addition, previous phytochemical studies on $M$. alba have demonstrated the presence of diverse chemical constituents including terpenoids, alkaloids, flavonoids (including chalcones and anthocyanins), phenolic acids, stilbenoids, and coumarins [38]. However, few previous studies have investigated the chemical constituents of $M$. alba with antidiabetic or antiobesity effects and their underlying mechanisms of action, despite many studies on the pharmacological effects of $M$. alba extracts.

In this context, our group has focused on the potentially bioactive natural components of $M$. alba. In our previous chemical investigation of $M$. alba fruits, we identified a new oxolane derivative, odisolane, and five heterocyclic compounds [39], some of which showed significant antiangiogenic activity mediated by decreasing p-Akt, vascular endothelial growth factor (VEGF), and phosphorylated, extracellular-signal-regulated kinase (phosphoERK) protein expression. Furthermore, we identified two indole acetic acid derivatives and flavonoids from M. alba fruits and found that a two-indole acetic acid derivative exhibited cytotoxicity against human cervical cancer HeLa cells through the activation of caspase- 8 and -9 , followed by cleavage of poly-ADP ribose polymerase (PARP) [40].

We also identified butyl pyroglutamate from $M$. alba fruits as a nephroprotective agent against cisplatin-induced kidney cell death in LLC-PK1, and its effect was found to be mediated by attenuation of the phosphorylation of c-Jun N-terminal kinase, MAPK, ERK, p38, and caspase-3 [41]. In particular, we recently found that loliolide, a heterocyclic compound in $M$. alba fruits, showed a protective effect against streptozotocin-induced apoptosis of INS-1 cells via inhibition of the caspase signaling pathway and induction of B-cell lymphoma-2 (Bcl-2) protein expression, suggesting that the active compound could be effective in preventing diabetes mellitus [42]. In the present study, the ethanol extract of M. alba fruits was further investigated to identify potential antidiabetic natural compounds, as there have been few studies on the antidiabetic compounds identified from M. alba and their underlying mechanisms of action, although it has been used in traditional medicine to lower blood sugar levels [36], and M. alba extracts are known to exhibit antidiabetic properties [37,38]. Phytochemical analysis led to the identification of two main compounds, rutin and quercetin-3-O- $\beta$-D-glucoside, and their structures were determined by detailed 
analysis of their nuclear magnetic resonance (NMR) spectroscopic and physical data, which were compared with previously reported values and mass spectrometry (MS) data from liquid chromatography (LC)-MS analysis. Herein, we report the exploration of the antidiabetic and anti-obesity potential of rutin and quercetin-3-O- $\beta$-D-glucoside (Q3G), focusing on glucose uptake through Akt and AMPK signaling, and lipid accumulation in 3T3-L1 adipocytes.

\section{Materials and Methods}

\subsection{Plant Material, Extraction, and Isolation}

The fruits of M. alba were purchased from Woori Herb in Kyungdong Market, the biggest medicinal herb market in Seoul, Korea, in January 2018. The material was authenticated by one of the authors (K.H.K.) and a voucher specimen (SSJ 2018-01) was deposited at the herbarium of the School of Pharmacy, Sungkyunkwan University, Suwon, Korea. The fruits of $M$. alba $(5.0 \mathrm{~kg}$ ) were dried, pulverized, subjected to extraction with $70 \%$ aqueous ethanol three times at room temperature, and filtered. The resultant filtrate was evaporated in vacuo to obtain the concentrated residue $(720 \mathrm{~g})$, which was dissolved in deionized water and solvent-partitioned with hexane, dichloromethane $\left(\mathrm{CH}_{2} \mathrm{Cl}_{2}\right)$, ethyl acetate (EtOAc), and $n$-butanol ( $\mathrm{BuOH}, 800 \mathrm{~mL}$, three times). Three solvent-partitioned fractions with increasing polarity were obtained: hexane $(13.5 \mathrm{~g})-$, chloroform $\left(\mathrm{CHCl}_{3}\right.$, $41.2 \mathrm{~g})-$, and $n$ - $\mathrm{BuOH}(68.3 \mathrm{~g})$-soluble.

The $n$ - $\mathrm{BuOH}$-soluble fraction $(65.0 \mathrm{~g})$, the major fraction, was separated using an HP-20 dianion column and washed with water $\left(\mathrm{H}_{2} \mathrm{O}\right)$ and methanol $(\mathrm{MeOH})$ to obtain two fractions: $\mathrm{MeOH}$-soluble $(8.2 \mathrm{~g}$ ) and water-soluble $(56.8 \mathrm{~g})$ fractions. The $\mathrm{MeOH}$ fraction $(8.2 \mathrm{~g})$ was separated into five fractions (A-E) using silica gel open-column chromatography with $\mathrm{CH}_{2} \mathrm{Cl}_{2}: \mathrm{MeOH}: \mathrm{H}_{2} \mathrm{O}$ (9:3:0.1). Fraction $\mathrm{B} 3(158 \mathrm{mg})$ was separated using preparative reversed-phase (RP) HPLC equipped with a Waters 996 photodiode array detector using an Agilent Eclipse C18 column $(21.2 \times 250 \mathrm{~mm}$; flow rate: $5 \mathrm{~mL} / \mathrm{min})$ with $30 \%$ $\mathrm{MeOH}$ to obtain seven subfractions (B31-B37). Fraction B35 $(15.5 \mathrm{mg})$ was purified using semi-preparative Shimadzu prominence HPLC system with SPD-20A/20AV series prominence HPLC UV-Vis detectors using a Phenomenex Luna HPLC phenyl-hexyl column $(250 \times 10 \mathrm{~mm}$; flow rate: $2 \mathrm{~mL} / \mathrm{min})$ with $30 \% \mathrm{MeOH}$ to isolate Q3G $\left(2.7 \mathrm{mg}\right.$, $\left.t_{\mathrm{R}}=34.0 \mathrm{~min}\right)$. Fraction D (0.3 g) was subjected to RP- $\mathrm{C}_{18}$ silica gel open-column chromatography with $50 \% \mathrm{MeOH}$ to obtain four subfractions (D1-D4), and subfraction D4 (43.3 mg) was further separated using the semi-preparative RP HPLC with the Phenomenex Luna HPLC phenylhexyl column $(250 \times 10 \mathrm{~mm}$; flow rate: $2 \mathrm{~mL} / \mathrm{min})$ and $18 \%$ acetonitrile $(\mathrm{MeCN})$ to yield rutin $\left(3.8 \mathrm{mg}, t_{\mathrm{R}}=21.5 \mathrm{~min}\right)$.

\subsection{Chemical Reagents}

Dulbecco's modified Eagle's medium/high glucose (DMEM/HG), fetal bovine serum (FBS), penicillin-streptomycin, and newborn calf serum were purchased from Thermo Fisher Scientific (Waltham, MA, USA), while 3-(4,5 Dimethylthiazol-2-yl)-2,5 diphenyltetrazolium bromide (MTT), isopropanol, dimethyl sulfoxide (DMSO), and 3-isobutyl1-methylxanthine (IBMX) were obtained from Merck Millipore (Burlington, MA, USA). Dexamethasone, $10 \%$ formalin, phosphate-buffered saline (PBS), insulin, and Oil-Red-O were purchased from Sigma-Aldrich (St. Louis, MO, USA). Rosiglitazone and 2-deoxy-2-((7nitro-2,1,3-benzoxadiazol-4-yl)amino)-D-glucose (2-NBDG) were purchased from Cayman Chemical (Ann Arbor, MI, USA). Antibodies against $\beta$-actin, Akt, phospho-Akt (Ser473), AMPK $\alpha$, and phospho-AMPK $\alpha$ (Thr172) were purchased from Cell Signaling Technology (Danvers, MA, USA). Peroxidase-conjugated goat anti-rabbit and goat anti-mouse IgG were obtained from Merck Millipore.

\subsection{T3-L1 Preadipocyte Differentiation}

To induce differentiation, preadipocytes were allowed to reach confluency (defined as day 0 ) and then, 2 days later, they were cultured in differentiation initiation medium (DIM) 
comprising DMEM/HG supplemented with $10 \mu \mathrm{g} / \mathrm{mL}$ insulin, $1 \mu \mathrm{M}$ dexamethasone, $0.5 \mathrm{mM} 3$-isobutyl-1-methylxanthine (IBMX), and 10\% FBS. After 2 days (defined as day 2), the culture medium was changed to differentiation progression medium (DPM) comprising DMEM/HG possessing 10\% FBS and $10 \mu \mathrm{g} / \mathrm{mL}$ insulin for 2 days. Then, on day 4 , the cells were maintained in post-differentiation medium (FM) comprising DMEM/HG supplemented with $10 \% \mathrm{FBS}$ and $1 \% \mathrm{P} / \mathrm{S}$, which was replaced every 2 days. Adipocytes were allowed to mature for 8 days after initiating differentiation.

\subsection{Cell Viability Assay}

First, 3T3-L1 ells were seeded at a density of $1 \times 10^{4}$ cells/well in 96-well plates for $24 \mathrm{~h}$ with complete cellular attachment. Compounds were diluted with medium to the indicated concentrations $(5 \mu \mathrm{M}$ and $10 \mu \mathrm{M})$ and added to individual wells with three replicates, followed by $48 \mathrm{~h}$ incubation at $37^{\circ} \mathrm{C}$ in a humidified atmosphere of $5 \%$ $\mathrm{CO}_{2}$. Then, $20 \mu \mathrm{L}$ MTT ( $5 \mathrm{mg} / \mathrm{mL}$ ) was added to the sample medium, followed by $2 \mathrm{~h}$ incubation. The liquid in the plate was discarded, $100 \mu \mathrm{L}$ DMSO was added to dissolve the MTT-formazan complex formed by shaking for $10 \mathrm{~min}$, and then the optical density was measured at a wavelength of $540 \mathrm{~nm}$. The percentage viable cells were calculated relative to the viability of untreated, which was set to $100 \%[43,44]$.

\subsection{Glucose Uptake Assay}

Glucose uptake into adipocytes was measured using a modified version of the method described by Alonso-Castro et al. [45]. Briefly, on differentiation day 8, adipocytes were incubated for $24 \mathrm{~h}$ with the respective test solution in DMEM (serum and glucose-free). After $1 \mathrm{~h}$ stimulation with or without insulin, $80 \mu \mathrm{M}$ of the fluorescent glucose analog 2-NBDG was added, and the culture was incubated for a further $1 \mathrm{~h}$. The uptake of 2-NBDG was stopped by washing the cells with pre-cooled $1 \times$ PBS. The remaining fluorescence activity of the cell monolayers was recorded on a fluorescence microplate reader at wavelengths of 485 (excitation) and 535 (emission) nm. Fluorescence activity in the absence of 2-NBDG was subtracted from all values obtained.

\subsection{Western Blot Analysis}

The cells were washed with ice-cold PBS, collected by centrifugation, and the resulting cell pellet was resuspended in lysis buffer $(1 \times$ radioimmunoprecipitation assay (RIPA) lysis buffer), $50 \mathrm{mM}$ Tris hydrochloride $(\mathrm{HCl}), 150 \mathrm{mM}$ sodium chloride $(\mathrm{NaCl}), 1.0 \%$ $(v / v) 0.1 \%(w / v)$ sodium dodecyl sulfate (SDS), $1.0 \mathrm{mM}$ ethylenediaminetetraacetic acid (EDTA), NP-40, $0.5 \%(w / v)$ sodium deoxycholate, $0.01 \%(w / v)$ sodium azide at a $\mathrm{pH} 7.4$, and $1 \times$ protease inhibitor cocktail), followed by incubation on ice for $1 \mathrm{~h}$. After the cell waste was eliminated by centrifugation, the lysate protein concentrations were measured using the Bio-Rad protein assay reagent (Hercules, CA, USA). Cell lysates were then separated using electrophoresis with $10 \%$ polyacrylamide gels containing SDS and transferred onto an Immune-Blot polyvinylidene fluoride (PVDF) membrane. The membranes were blocked by incubation in Tris-buffered saline plus $0.01 \%$ Tween 20 (TBST) containing 5\% nonfat dry milk for $1 \mathrm{~h}$ at room temperature. The immunoblots were then incubated with primary antibodies (Akt, AMPK, phospho-Akt, phospho-AMPK, and $\beta$-actin; 1:1000 or 1:2000) overnight at $4{ }^{\circ} \mathrm{C}$, followed by secondary antibody (peroxidase-conjugated goat anti-rabbit or goat anti-mouse IgG, 1:2000). The immunoblots were visualized by immersion in an enhanced chemiluminescence (ECL) solution for $5 \mathrm{~min}$, followed by scanning with a ChemiDoc imaging system (Bio-Rad, Hercules, CA, USA).

\subsection{Oil-Red-O Staining}

Lipid accumulation was measured in 3T3-L1 adipocytes using Oil-Red-O staining. Adipocyte differentiation was induced for 8 days, as described above. On day 8 , the adipocytes were washed two times with PBS and fixed with $10 \%$ formalin for $30 \mathrm{~min}$ in a culture plate with wells. Each well was washed with distilled water and stained with a 
$0.5 \%$ Oil-Red-O solution in $100 \%$ isopropanol. After $30 \mathrm{~min}$, the cells were washed two times with distilled water and examined under a phase-contrast microscope. Cells were considered lipid-positive when the droplets were stained red. To quantify the cellular lipid content, the Oil-Red-O staining was washed with $100 \%$ isopropanol, shaken at room temperature for $30 \mathrm{~min}$, and then the Oil-Red-O in the supernatant was recorded on a SpectraMax ${ }^{\circledR}$ M3 microplate reader at a wavelength of $520 \mathrm{~nm}$ (Molecular Devices, San Jose, CA, USA).

\subsection{Statistical Analysis}

All experiments were conducted in triplicate and the data are stated as the means \pm standard error of the mean (SEM). Differences between mean values were analyzed by applying the Student's $t$-test. Statistical significance was set at $p<0.05$.

\section{Results}

\subsection{Isolation of Compounds}

The M. alba fruits were subjected to extraction with $70 \%$ aqueous ethanol using a rotary evaporator to obtain the ethanolic extract. The obtained crude extract was sequentially solvent-partitioned using the following four organic solvents with increasing polarity, hexane, $\mathrm{CH}_{2} \mathrm{Cl}_{2}$, EtOAc, and $n$ - $\mathrm{BuOH}$, to obtain solvent fractions. LC/MS/UV-based analysis of the fractions revealed that the $n$ - $\mathrm{BuOH}$-soluble fraction contains two major peaks with molecular ion peaks at $m / z 611[\mathrm{M}+\mathrm{H}]^{+}$and $m / z 465[\mathrm{M}+\mathrm{H}]^{+}$exhibiting a characteristic UV spectrum of flavonoid ( $\lambda_{\max } 205,255$, and $355 \mathrm{~nm}$ ). LC/MS/UV-guided fractionation of the $\mathrm{BuOH}$-soluble fraction was performed using repeated open-column chromatography and HPLC purification by LC/MS monitoring to isolate the major peaks. The final semi-preparative HPLC separation monitored by LC/MS yielded two main compounds: rutin [46] and quercetin-3-O- $\beta$-D-glucoside (Q3G) [47]. Their structures (Figure 1) were determined by comparing their ${ }^{1} \mathrm{H}$ and ${ }^{13} \mathrm{C}$ NMR spectra with those previously reported in the literature [46,47] and our in-house UV library. NMR spectra were recorded using a Bruker AVANCE III 700 NMR spectrometer operating at $700 \mathrm{MHz}$ $\left({ }^{1} \mathrm{H}\right)$ and $175 \mathrm{MHz}\left({ }^{13} \mathrm{C}\right)$. An Agilent 1200 series HPLC system equipped with a diode array detector and a 6130 series electrospray ionization (ESI) mass spectrometer was used for LC/MS analysis, using an analytical Kinetex $C_{18} 100 \AA$ A column $(100 \times 2.1 \mathrm{~mm}, 5 \mu \mathrm{m}$; flow rate: $0.3 \mathrm{~mL} / \mathrm{min}$ ). The molecular ions of the compounds detected using LC/MS led us to confirm the structural elucidation. Rutin and Q3G are commercially available. However, the application of LC/MS/UV-guided fractionation used in this study will be helpful to obtain these compounds in significant quantities without the costs.

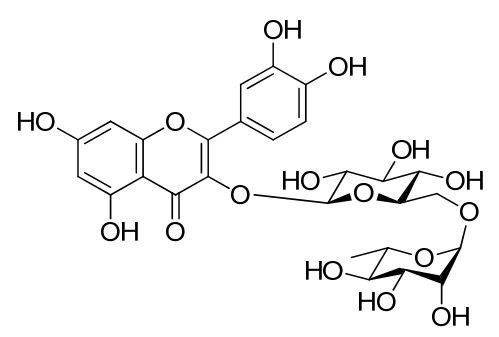

rutin<smiles></smiles>

Q3G

Figure 1. Chemical structures of rutin and quercetin-3-O- $\beta$-D-glucoside (Q3G).

\subsection{Effect of Rutin and Q3G on 3T3-L1 Cell Viability}

The MTT method was used to determine the cell viability of rutin and Q3G in 3T3-L1 preadipocytes cultured for $24 \mathrm{~h}$, followed by incubation with the compounds at a concentration of up to $10 \mu \mathrm{M}$ for $48 \mathrm{~h}$. Within the range of tested concentrations $(1.25-10 \mu \mathrm{M})$, rutinand Q3G-treated cells exhibited similar viability to the untreated control cells (Figure 2). Based on these results, we further studied the two highest concentrations ( 5 and $10 \mu \mathrm{M})$ of each compound. 


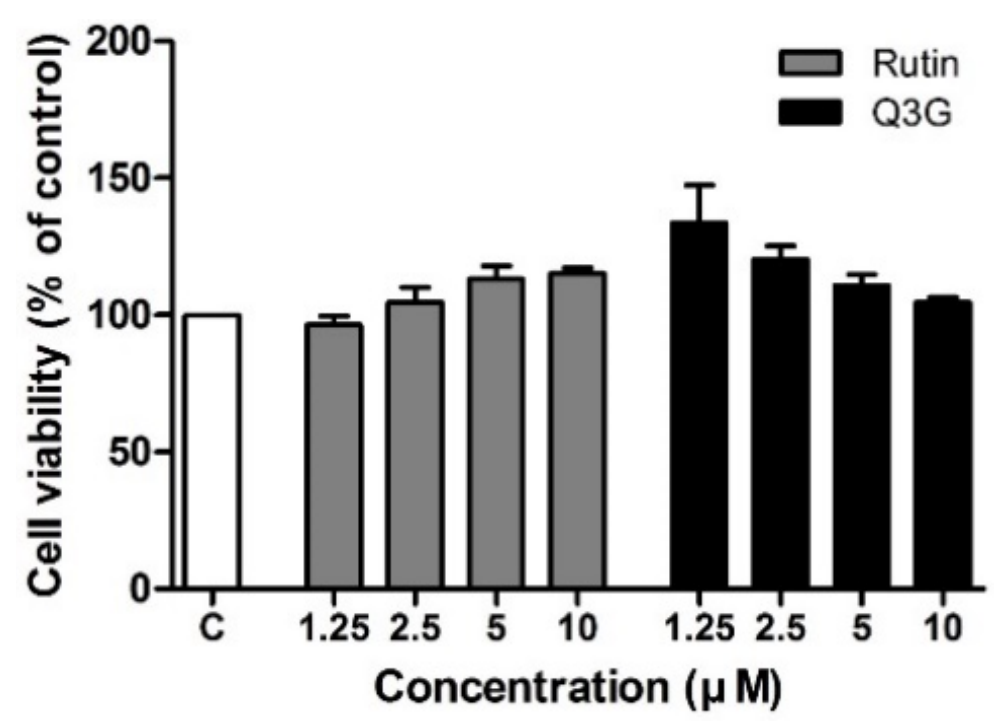

Figure 2. Effect of rutin and quercetin-3-O- $\beta$-D-glucoside (Q3G) on cell viability of 3T3-L1 adipocytes treated for $48 \mathrm{~h}$. Data are means \pm standard error of the mean (SEM, $n=3$ ).

\subsection{Effect of Rutin and Q3G on Glucose Uptake in Differentiated 3T3-L1 Adipocytes}

Glucose transport into adipocytes and other cells is one of the primary metabolic effects mediated by insulin [48]. We investigated the effects of rutin and Q3G on glucose uptake in differentiated 3T3-L1 adipocytes, with or without insulin. As shown in Figure 3, rutin improved insulin-stimulated uptake of 2-deoxy-2-((7-nitro-2,1,3-benzoxadiazol-4yl)amino)-D-glucose (2-NBDG) by approximately 1.3 times compared to the control group, which only showed statistical significance at $5 \mu \mathrm{M}(p<0.01)$. Furthermore, Q3G at concentrations of 5 and $10 \mu \mathrm{M}$ significantly improved glucose uptake by $1.3(p<0.05)$ and $1.6(p<0.01)$ times, respectively. Relatively higher glucose uptake was also observed with Q3G treatment than with rutin in the absence of insulin, but these differences were not statistically significant.

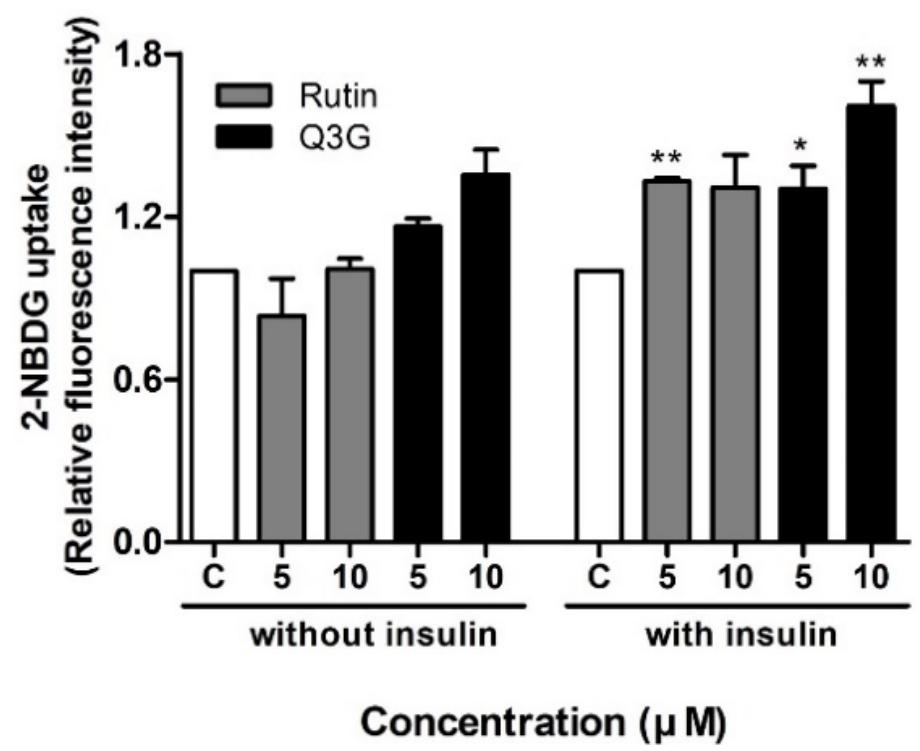

Figure 3. Effect of rutin and quercetin-3-O- $\beta$-D-glucoside (Q3G) on basal and insulin-stimulated (100 nM) 2-deoxy-2-((7-nitro-2,1,3-benzoxadiazol-4-yl)amino)-D-glucose (2-NBDG) uptake in differentiated 3T3-L1 adipocytes. Data are means \pm standard error of the mean (SEM, $n=3) ;{ }^{*} p<0.05$ and ** $p<0.01$ versus control. C, control. 


\subsection{Effect of Rutin and Q3G on Akt or AMPK Phosphorylation}

To elucidate the mechanism by which rutin and Q3G induce insulin-stimulated glucose uptake, we assessed the activation of Akt and AMPK phosphorylation. As shown in Figure 4, both compounds significantly increased phospho-Akt expression in 3T3-L1 adipocytes. In particular, the Q3G-activated Akt phosphorylation level was 140\% (at $5 \mu \mathrm{M}$ ) and $200 \%($ at $10 \mu \mathrm{M})$ that of the control level, respectively (both $p<0.05)$. In the case of AMPK phosphorylation, at both concentrations, rutin augmented the expression level of phospho-AMPK in insulin-stimulated 3T3-L1 adipocytes, whereas no significant change was observed with Q3G (Figure 5).

(A)

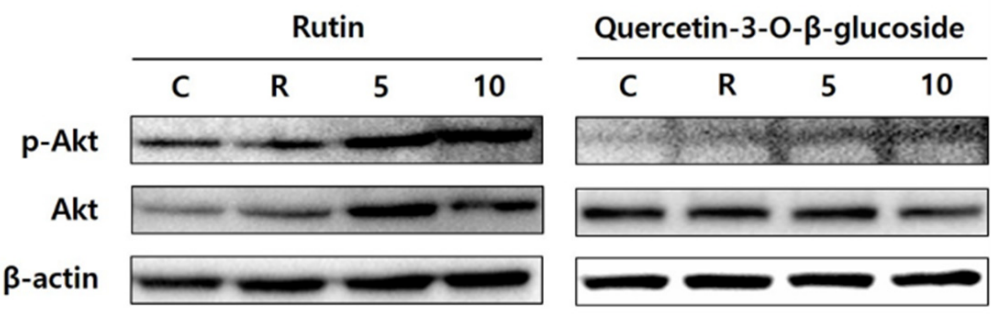

(B)

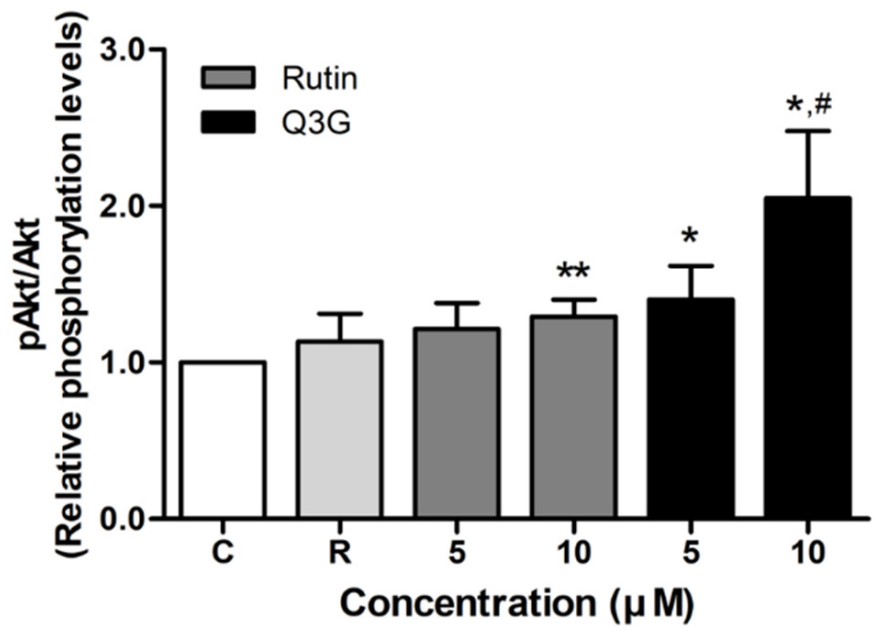

Figure 4. Effect of rutin and quercetin-3-O- $\beta$-D-glucoside (Q3G) on Akt phosphorylation in insulinstimulated 3T3-L1 adipocytes. (A) Representative Western blots of Akt and phosphorylated (phosphoAkt). (B) Quantification of relative phosphorylation levels of Akt. Levels of phospho-Akt were normalized to total Akt for each compound. Data are means \pm standard error of the mean (SEM, $n=3)$; ${ }^{*} p<0.05$ and ${ }^{* *} p<0.01$ versus control. \# $p<0.05$ versus rosiglitazone $10 \mu \mathrm{M}$. C, control; $\mathrm{R}$, rosiglitazone $10 \mu \mathrm{M}$.

\subsection{Effect of Rutin and Q3G on Lipid Accumulation}

The effects of rutin and Q3G on lipid accumulation in differentiated 3T3-L1 adipocytes were determined using Oil-Red-O staining (Figure 6). The number of lipid droplets in 3T3-L1 cells increased considerably after treatment with rosiglitazone (Figure 6B), with significantly higher lipid accumulation than in the control (Figure $6 \mathrm{G}, p<0.01$ ). However, rutin-treated (Figure 6C,D) and Q3G-treated (Figure 6E,F) cells exhibited similar levels of lipid accumulation to the control, indicating that they had no effect on lipid accumulation in 3T3-L1 adipocytes. 
(A)

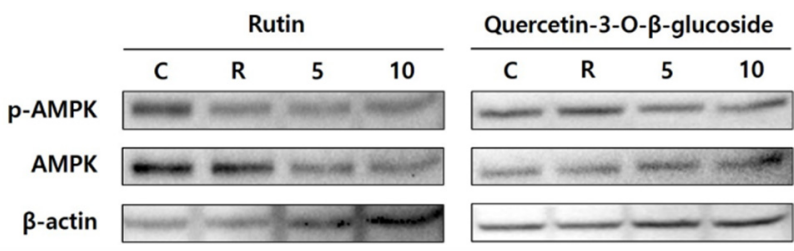

(B)

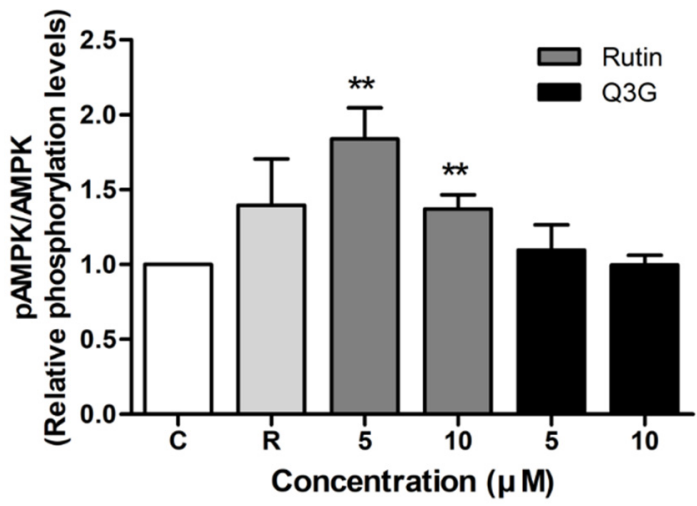

Figure 5. Effect of rutin and quercetin-3-O- $\beta$-D-glucoside (Q3G) on AMP-activated protein kinase (AMPK) phosphorylation in insulin-stimulated 3T3-L1 adipocytes. (A) Representative Western blots for AMPK and phospho-AMPK. (B) Quantification of relative phosphorylation levels of AMPK. Phospho-AMPK level was normalized to total AMPK for each compound. Data are means \pm standard error of the mean (SEM, $n=3$ ); ${ }^{* *} p<0.01$ versus control. C, control. R, rosiglitazone $10 \mu \mathrm{M}$.
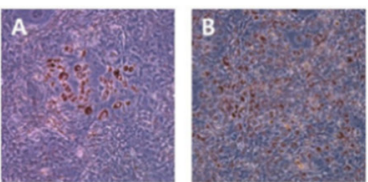

(G)
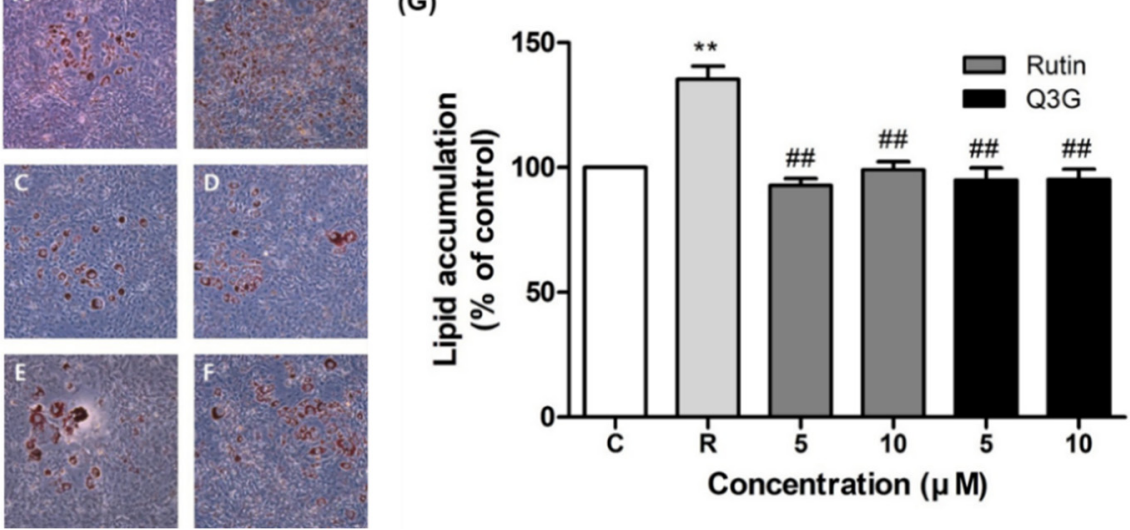

Figure 6. Representative images (magnification $\times 100$ ) of Oil-Red-O staining in 3T3-L1 cells treated with (A) vehicle (control), (B) rosiglitazone $10 \mu \mathrm{M},(\mathbf{C})$ rutin $5 \mu \mathrm{M},(\mathbf{D})$ rutin $10 \mu \mathrm{M}$, (E) quercetin-3-O$\beta$-D-glucoside (Q3G) $5 \mu \mathrm{M}$, and (F) Q3G $10 \mu \mathrm{M}$ (F). (G) Effect of rutin and Q3G on lipid accumulation in 3T3-L1 adipocytes. Data are means \pm standard error of the mean (SEM, $n=3)$; ${ }^{* *} p<0.01$ versus control and \#\# $p<0.01$ versus rosiglitazone $10 \mu \mathrm{M}$. C, control; R, rosiglitazone $10 \mu \mathrm{M}$.

\section{Discussion}

Insulin resistance plays a key role in the development of T2D and metabolic syndrome [49], which is a complex and chronic progressive syndrome that leads to adverse effects in many organs. Over the past few years, several studies have revealed that controlling whole-body glucose homeostasis in both normal and diseased states plays an essential role in adipose tissue [50]. Because currently marketed synthetic antidiabetic and anti-obesity agents often cause unexpected adverse effects [51], natural products with fewer side effects are attracting great attention for the treatment of diabetes and obesity. In 
this study, we investigated whether rutin and Q3G, the major active compounds isolated from $M$. alba fruits, can be used as natural-based therapeutic agents for T2D using a model of 3T3-L1 adipocytes. These two constituents are the major glycosides of quercetin and widely distributed in nature [52]. There have been various studies to determine their health-promoting effects [52], where it has been found that rutin possesses antioxidant, anti-inflammatory, anti-angiogenic, and organ-protective activities [53-60]. Furthermore, a recent review demonstrated that rutin exerts an anti-hyperglycemic effect through the following mechanisms [61]: (1) reduces glucose absorption from the small intestine by $\alpha$ glucosidases and $\alpha$-amylase inhibition; (2) increases glucose uptake in muscle and adipose tissue by stimulating GLUT4 synthesis and translocation, activating PI3K- and MAPKmediated signaling pathways, and increasing peroxisome proliferator-activated receptor gamma (PPAR $\gamma$ ) expression; (3) exhibits the reversal of gluconeogenesis by inhibiting the gene expression of key gluconeogenic enzymes, such as glucose-6-phophatase (G6Pase), glycogen phosphorylase, and fructose-1,6-bisphosphatase, and (4) shows suppression of glucotoxicity by IRS2 and AMPK signaling pathway activation. Although relatively few studies on Q3G have been reported, Q3G also exhibited a broad range of physiological properties, including antioxidant, anti-inflammatory, antidiabetic, anti-angiogenic, and chemopreventive activity [52].

Impaired glucose transport is associated with insulin resistance in T2D patients. In this study, the effects of rutin and Q3G on basal and insulin-stimulated glucose uptake into fully differentiated 3T3-L1 adipocytes were examined using non-radioactive measurement of 2-NBDG uptake. The results showed that rutin and Q3G significantly increased insulin-stimulated 2-NBDG glucose uptake. As mentioned above, each glucose transporter isoform controls glucose uptake in a different way. In adipocytes, GLUT4, a representative insulin-sensitive glucose transporter, is translocated from the intracellular vesicle to the cell membrane and modulates glucose utilization [62]. A recent study has reported that the regulation of GLUT4 expression and translocation is affected by various factors, such as adiponectin and insulin signaling mediators [63]. Although we have found that the GLUT4 protein expression in insulin-stimulated 3T3-L1 adipocytes was unchanged after rutin and Q3G treatment (data not shown), these results were limited to total protein expression and further research on the extent of GLUT4 translocation from cytosol to plasma membrane is needed. Insulin signaling upstream proteins, such as insulin receptors, PI3K, should also be evaluated to clarify the mechanisms of the insulin-mimetic actions.

The major mechanism of glucose uptake is the rapid translocation of GLUT4 protein from the cytosol to the plasma membrane through the insulin signaling pathway. In this pathway, the intracellular tyrosine residues of the insulin receptor $\beta$-subunit are autophosphorylated and activate downstream signaling molecules including IRS-1 and PI3K. Subsequent phosphorylation of Akt promotes the translocation of glucose transporters to the plasma membrane $[3,64]$. In addition to the insulin signaling pathway, the AMPKmediated pathway is also involved in glucose transport in muscles and adipocytes [65]. Various AMPK activators, such as 5-aminoimidazole-4-carboxy-amide-1-d-ribofuranoside (AICAR) and metformin, have been reported to enhance glucose uptake in adipocytes through AMPK activation $[19,66]$. Although these AMPK agonists elevate both insulinindependent and insulin-dependent glucose uptake $[67,68]$, cooperation between AMPK and the insulin signaling pathway on glucose uptake in adipocytes is controversial [69]. In this study, we found that Q3G showed a dose-proportional, specific increase in Akt phosphorylation. To our best knowledge, this is the first report to confirm that Q3G regulates glucose uptake through activation of the Akt-mediated signaling pathway, while rutin significantly increased both Akt and AMPK phosphorylation, which is consistent with a previous study performed in rat pancreatic $\beta$ cells [70]. This observation suggests the possible simultaneous activation of AMPK and the insulin signaling pathway in controlling glucose uptake.

At the end of adipogenesis, pre-adipocytes (spindle-shaped) change their forms into a round shape, performing various endocrine functions, such as lipid accumulation, glucose 
uptake promotion in response to insulin, fatty acid synthesis, and secretion of various hormones and cytokines [71]. Thus, intracellular lipid accumulation is generally used as a primary indicator for adipogenesis [72]. The differentiation and maturation of adipocytes and lipid accumulation are also related to the development of obesity [73]. TZDs, such as rosiglitazone, promote insulin-sensitizing action through the activation of PPAR $\gamma$, which regulates adipocyte differentiation and adipocyte-specific gene expression [74]. Therefore, the use of TZDs for the treatment of T2D can cause unexpected side effects (weight gain) and increase the risk of obesity [75]. Unlike rosiglitazone, rutin and Q3G showed no change in lipid accumulation in 3T3-L1 adipocytes in this study, suggesting that they could be safely used without the risk of body-weight-related side effects and obesity.

\section{Conclusions}

In this study, we isolated rutin and Q3G, as the major active compounds of M. alba fruits, and found that these compounds improved glucose uptake via the Akt-mediated insulin signaling pathway and/or AMPK activation. The active compounds also positively affected lipid accumulation in adipocytes, suggesting that glucose uptake was mediated through activation of the Akt and AMPK signaling pathway without induction of adipogenesis. Based on these findings, we conclude that rutin and Q3G, active components of M. alba fruits, have the potential to induce fewer side effects such as weight gain than rosiglitazone, an available antidiabetic drug. Therefore, these compounds could be potential therapeutic candidates for the management of T2D.

Author Contributions: Conceptualization, C.-I.C. and K.H.K.; formal analysis, S.H.L., J.S.Y., and H.S.L.; investigation, S.H.L., J.S.Y., and H.S.L.; writing—original draft preparation, C.-I.C. and K.H.K.; writing-review and editing, C.-I.C. and K.H.K.; visualization, S.H.L., J.S.Y., and H.S.L.; supervision, C.-I.C. and K.H.K.; project administration, C.-I.C. and K.H.K.; funding acquisition, K.H.K. All authors have read and agreed to publishing this version of the manuscript.

Funding: This work was supported by a grant from the National Research Foundation of Korea (NRF), funded by the Korean government (MSIT) (grant number: 2019R1A5A2027340). This research was also supported by the BK21 FOUR program through the National Research Foundation (NRF) of Korea funded by the Ministry of Education (MOE, Korea).

Institutional Review Board Statement: Not applicable.

Informed Consent Statement: Not applicable.

Data Availability Statement: Not applicable.

Conflicts of Interest: The authors declare no conflict of interest.

\section{References}

1. Wild, S.; Roglic, G.; Green, A.; Sicree, R.; King, H. Global prevalence of diabetes: Estimates for the year 2000 and projections for 2030. Diabetes Care 2004, 27, 1047-1053. [CrossRef] [PubMed]

2. Joost, H.-G.; Thorens, B. The extended GLUT-family of sugar/polyol transport facilitators: Nomenclature, sequence characteristics, and potential function of its novel members. Mol. Membr. Biol. 2001, 18, 247-256. [CrossRef] [PubMed]

3. Watson, R.T.; Kanzaki, M.; Pessin, J.E. Regulated Membrane Trafficking of the Insulin-Responsive Glucose Transporter 4 in Adipocytes. Endocr. Rev. 2004, 25, 177-204. [CrossRef]

4. Herman, M.A.; Kahn, B.B. Glucose transport and sensing in the maintenance of glucose homeostasis and metabolic harmony. J. Clin. Investig. 2006, 116, 1767-1775. [CrossRef]

5. Cong, L.-N.; Chen, H.; Li, Y.; Zhou, L.; McGibbon, M.A.; Taylor, S.I.; Quon, M.J. Physiological Role of Akt in Insulin-Stimulated Translocation of GLUT4 in Transfected Rat Adipose Cells. Mol. Endocrinol. 1997, 11, 1881-1890. [CrossRef] [PubMed]

6. Cushman, S.W.; Wardzala, L.J. Potential mechanism of insulin action on glucose transport in the isolated rat adipose cell. Apparent translocation of intracellular transport systems to the plasma membrane. J. Biol. Chem. 1980, 255, 4758-4762. [CrossRef]

7. Wiernsperger, N. Is non-insulin dependent glucose uptake a therapeutic alternative? Part 1: Physiology, mechanisms and role of non insulin-dependent glucose uptake in type 2 diabetes. Diabetes Metab. 2005, 31, 415-426. [CrossRef]

8. Sesti, G. Pathophysiology of insulin resistance. Best Pract. Res. Clin. Endocrinol. Metab. 2006, 20, 665-679. [CrossRef]

9. Newgard, C.B.; Hirsch, L.J.; Foster, D.W.; McGarry, J.D. Studies on the mechanism by which exogenous glucose is converted into liver glycogen in the rat. A direct or an indirect pathway? J. Biol. Chem. 1983, 258, 8046-8052. [CrossRef] 
10. De Meyts, P.; Whittaker, J. Structural biology of insulin and IGF1 receptors: Implications for drug design. Nat. Rev. Drug Discov. 2002, 1, 769-783. [CrossRef]

11. White, M.F. IRS proteins and the common path to diabetes. Am. J. Physiol. Endocrinol. Metab. 2002, 283, E413-E422. [CrossRef]

12. Alessi, D.R.; Downes, C.P. The role of PI 3-kinase in insulin action. Biochim. Biophys. Acta BBA Mol. Cell Biol. Lipids 1998, 1436, 151-164. [CrossRef]

13. Vanhaesebroeck, B.; Alessi, D.R. The PI3K-PDK1 connection: More than just a road to PKB. Biochem. J. 2000, 346, 561-576.

14. Beeson, M.; Sajan, M.P.; Dizon, M.; Grebenev, D.; Gomez-Daspet, J.; Miura, A.; Kanoh, Y.; Powe, J.; Bandyopadhyay, G.; Standaert, M.L.; et al. Activation of Protein Kinase C-by Insulin and Phosphatidylinositol-3,4,5-(PO4) 3 Is Defective in Muscle in Type 2 Diabetes and Impaired Glucose Tolerance: Amelioration by Rosiglitazone and Exercise. Diabetes 2003, 52, 1926-1934. [CrossRef]

15. Gonzalez, E.; McGraw, T.E. Insulin-modulated Akt subcellular localization determines Akt isoform-specific signaling. Proc. Natl. Acad. Sci. USA 2009, 106, 7004-7009. [CrossRef]

16. Gr, S.; Be, K. amPK in health and disease. Physiol. Rev. 2009, 89, 1025-1078.

17. Ruderman, N.B.; Carling, D.; Prentki, M.; Cacicedo, J.M. AMPK, insulin resistance, and the metabolic syndrome. J. Clin. Investig. 2013, 123, 2764-2772. [CrossRef] [PubMed]

18. Fryer, L.G.D.; Parbu-Patel, A.; Carling, D. The Anti-diabetic Drugs Rosiglitazone and Metformin Stimulate AMP-activated Protein Kinase through Distinct Signaling Pathways. J. Biol. Chem. 2002, 277, 25226-25232. [CrossRef] [PubMed]

19. Yamaguchi, S.; Katahira, H.; Ozawa, S.; Nakamichi, Y.; Tanaka, T.; Shimoyama, T.; Takahashi, K.; Yoshimoto, K.; Imaizumi, M.O.; Nagamatsu, S.; et al. Activators of AMP-activated protein kinase enhance GLUT4 translocation and its glucose transport activity in 3T3-L1 adipocytes. Am. J. Physiol. Endocrinol. Metab. 2005, 289, E643-E649. [CrossRef] [PubMed]

20. Rosen, E.D.; Spiegelman, B.M. What We Talk About When We Talk About Fat. Cell 2014, 156, 20-44. [CrossRef] [PubMed]

21. Steinberger, J.; Stephen, R.D. Obesity, Insulin Resistance, Diabetes, and Cardiovascular Risk in Children. Circulation 2003, 107, 1448-1453. [CrossRef]

22. Qatanani, M.; Lazar, M.A. Mechanisms of obesity-associated insulin resistance: Many choices on the menu. Genes Dev. 2007, 21, 1443-1455. [CrossRef]

23. Guilherme, A.; Virbasius, J.V.; Puri, V.; Czech, M.P. Adipocyte dysfunctions linking obesity to insulin resistance and type 2 diabetes. Nat. Rev. Mol. Cell Biol. 2008, 9, 367-377. [CrossRef]

24. Vázquez-Vela, M.E.F.; Torres, N.; Tovar, A.R. White Adipose Tissue as Endocrine Organ and Its Role in Obesity. Arch. Med. Res. 2008, 39, 715-728. [CrossRef]

25. Sethi, J.K.; Vidal-Puig, A. Visfatin: The missing link between intra-abdominal obesity and diabetes? Trends Mol. Med. 2005, 11, 344-347. [CrossRef] [PubMed]

26. Parulkar, A.A.; Pendergrass, M.L.; Granda-Ayala, R.; Lee, T.R.; Fonseca, V.A. Nonhypoglycemic effects of thiazolidinediones. Ann. Intern. Med. 2001, 134, 61-71. [CrossRef] [PubMed]

27. Lee, S.; Lee, D.; Ryoo, R.; Kim, J.C.; Park, H.B.; Kang, K.S.; Kim, K.H. Calvatianone, a Sterol Possessing a 6/5/6/5-Fused Ring System with a Contracted Tetrahydrofuran B-Ring, from the Fruiting Bodies of Calvatia nipponica. J. Nat. Prod. 2020, 83, 2737-2742. [CrossRef] [PubMed]

28. Lee, S.R.; Kang, H.S.; Yoo, M.J.; Yi, S.A.; Beemelmanns, C.; Lee, J.C.; Kim, K.H. Anti-adipogenic Pregnane Steroid from a Hydractinia-associated Fungus, Cladosporium sphaerospermum SW67. Nat. Prod. Sci. 2020, 26, 230-235.

29. Lee, S.; Ryoo, R.; Choi, J.H.; Kim, J.H.; Kim, S.H.; Kim, K.H. Trichothecene and tremulane sesquiterpenes from a hallucinogenic mushroom Gymnopilus junonius and their cytotoxicity. Arch. Pharm. Res. 2020, 43, 214-223. [CrossRef]

30. Trinh, T.A.; Park, E.J.; Lee, D.; Song, J.H.; Lee, H.L.; Kim, K.H.; Kim, Y.; Jung, K.; Kang, K.S.; Yoo, J.E. Estrogenic Activity of Sanguiin H-6 through Activation of Estrogen Receptor $\alpha$ Coactivator-binding Site. Nat. Prod. Sci. 2019, 25, 28-33. [CrossRef]

31. Ha, J.W.; Kim, J.; Kim, H.; Jang, W.; Kim, K.H. Mushrooms: An Important Source of Natural Bioactive Compounds. Nat. Prod. Sci. 2020, 26, 118-131.

32. De Padua, L.S.; Bunyapraphatsara, N.; Lemmens, R.H.M.J. Plant Resources of South-East Asia 12:(1) Medicinal and Poisonous Plants 1; Backhuys Publishers: Leiden, The Netherlands, 1999.

33. Suttie, J.M.; Reynolds, S.G.; Batello, C. Grasslands of the World; Food and Agriculture Organization: Rome, Italy, 2005 ; Volume 34.

34. Bae, S.-H.; Suh, H.-J. Antioxidant activities of five different mulberry cultivars in Korea. LWT Food Sci. Technol. 2007, 40, 955-962. [CrossRef]

35. Katsube, T.; Imawaka, N.; Kawano, Y.; Yamazaki, Y.; Shiwaku, K.; Yamane, Y. Antioxidant flavonol glycosides in mulberry (Morus alba L.) leaves isolated based on LDL antioxidant activity. Food Chem. 2006, 97, 25-31. [CrossRef]

36. Machii, H.; Koyama, A.; Yamanouchi, H. Mulberry for Animal Production. Mulberry breeding, cultivation and utilization in Japan. FAO Anim. Prod. Health Pap. 2002, 147, 63.

37. Chan, E.W.; Lye, P.-Y.; Wong, S.-K. Phytochemistry, pharmacology, and clinical trials of Morus alba. Chin. J. Nat. Med. 2016, 14, 17-30.

38. Ramappa, V.K.; Srivastava, D.; Singh, P.; Kumar, U.; Kumar, D.; Gosipatala, S.B.; Saha, S.; Kumar, D.; Raj, R. Mulberries: A Promising Fruit for Phytochemicals, Nutraceuticals, and Biological Activities. Int. J. Fruit Sci. 2020, 1-26. [CrossRef]

39. Lee, S.R.; Park, J.Y.; Yu, J.S.; Lee, S.O.; Ryu, J.Y.; Choi, S.Z.; Kang, K.S.; Yamabe, N.; Kim, K.H. Odisolane, a Novel Oxolane Derivative, and Antiangiogenic Constituents from the Fruits of Mulberry (Morus alba L.). J. Agric. Food Chem. 2016, 64, 3804-3809. [CrossRef] [PubMed] 
40. Yu, J.S.; Lee, D.; Lee, S.R.; Lee, J.W.; Choi, C.I.; Jang, T.S.; Kang, K.S.; Kim, K.H. Chemical characterization of cytotoxic indole acetic acid derivative from mulberry fruit (Morus alba L.) against human cervical cancer. Bioorg. Chem. 2018, 76, 28-36. [CrossRef]

41. Lee, D.; Yu, J.S.; Lee, S.R.; Hwang, G.S.; Kang, K.S.; Park, J.G.; Kim, H.Y.; Kim, K.H.; Yamabe, N. Beneficial effects of bioactive compounds in mulberry fruits against cisplatin-induced nephrotoxicity. Int. J. Mol. Sci. 2018, 19, 1117. [CrossRef]

42. Song, J.H.; Lee, D.; Lee, S.R.; Yu, J.S.; Jang, T.S.; Nam, J.W.; Kim, K.H.; Kang, K.S. Identification of bioactive heterocyclic compounds from mulberry and their protective effect against streptozotocin-induced apoptosis in INS-1 cells. Mol. Med. Rep. 2018, 17, 5982-5987. [CrossRef]

43. Xin, C.; Quan, H.; Kim, J.M.; Hur, Y.H.; Shin, J.Y.; Bae, H.B.; Choi, J.I. Ginsenoside Rb1 increases macrophage phagocytosis through p38 mitogen-activated protein kinase/Akt pathway. J. Ginseng Res. 2019, 43, 394-401. [CrossRef] [PubMed]

44. Li, J.; Wang, R.F.; Zhou, Y.; Hu, H.J.; Yang, Y.B.; Yang, L.; Wang, Z.T. Dammarane-type triterpene oligoglycosides from the leaves and stems of Panax notoginseng and their antiinflammatory activities. J. Ginseng Res. 2019, 43, 377-384. [CrossRef]

45. Alonso-Castro, A.J.; Miranda-Torres, A.C.; González-Chávez, M.M.; Salazar-Olivo, L.A. Cecropia obtusifolia Bertol and its active compound, chlorogenic acid, stimulate 2-NBDglucose uptake in both insulin-sensitive and insulin-resistant 3T3 adipocytes. J. Ethnopharmacol. 2008, 120, 458-464. [CrossRef]

46. Li, Y.L.; Li, J.; Wang, N.L.; Yao, X.S. Flavonoids and a new polyacetylene from Bidens parviflora Willd. Molecules 2008, 13, $1931-1941$. [CrossRef] [PubMed]

47. Han, J.T.; Bang, M.H.; Chun, O.K.; Kim, D.O.; Lee, C.Y.; Baek, N.I. Flavonol glycosides from the aerial parts of Aceriphyllum rossii and their antioxidant activities. Arch. Pharm. Res. 2004, 27, 390-395. [CrossRef] [PubMed]

48. Kahn, C.R.; Baird, K.L.; Flier, J.S.; Grunfeld, C.; Harmon, J.T.; Harrison, L.C.; Karlsson, F.A.; Kasuga, M.; King, G.L.; Lang, U.C.; et al. Insulin Receptors, Receptor Antibodies, and the Mechanism of Insulin Action. In Proceedings of the 1980 Laurentian Hormone Conference; Academic Press: Cambridge, MA, USA, 1981; pp. 477-538.

49. Szendroedi, J.; Phielix, E.; Roden, M. The role of mitochondria in insulin resistance and type 2 diabetes mellitus. Nat. Rev. Endocrinol. 2012, 8, 92-103. [CrossRef] [PubMed]

50. Rosen, E.D.; Spiegelman, B.M. Adipocytes as regulators of energy balance and glucose homeostasis. Nature 2006, 444, 847-853. [CrossRef] [PubMed]

51. Hollander, P. Anti-Diabetes and Anti-Obesity Medications: Effects on Weight in People with Diabetes. Diabetes Spectr. 2007, 20, 159-165. [CrossRef]

52. Valentová, K.; Vrba, J.; Bancírová, M.; Ulrichová, J.; Křen, V. Isoquercitrin: Pharmacology, toxicology, and metabolism. Food Chem. Toxicol. 2014, 68, 267-282. [CrossRef]

53. Yang, J.; Guo, J.; Yuan, J. In vitro antioxidant properties of rutin. LWT Food Sci. Technol. 2008, 41, 1060-1066. [CrossRef]

54. Selloum, L.; Bouriche, H.; Tigrine, C.; Boudoukha, C. Anti-inflammatory effect of rutin on rat paw oedema, and on neutrophils chemotaxis and degranulation. Exp. Toxicol. Pathol. 2003, 54, 313-318. [CrossRef] [PubMed]

55. Mellou, F.; Loutrari, H.; Stamatis, H.; Roussos, C.; Kolisis, F.N. Enzymatic esterification of flavonoids with unsaturated fatty acids: Effect of the novel esters on vascular endothelial growth factor release from K562 cells. Process Biochem. 2006, 41, 2029-2034. [CrossRef]

56. La Casa, C.; Villegas, I.; Alarcón de la Lastra, C.; Motilva, V.; Martín Calero, M.J. Evidence for protective and antioxidant properties of rutin, a natural flavone, against ethanol induced gastric lesions. J. Ethnopharmacol. 2000, 71, 45-53. [CrossRef]

57. Janbaz, K.H.; Saeed, S.A.; Gilani, A.H. Protective effect of rutin on paracetamol- and CCl4-induced hepatotoxicity in rodents. Fitoterapia 2002, 73, 557-563. [CrossRef]

58. Richetti, S.K.; Blank, M.; Capiotti, K.M.; Piato, A.L.; Bogo, M.R.; Vianna, M.R.; Bonan, C.D. Quercetin and rutin prevent scopolamine-induced memory impairment in zebrafish. Behav. Brain Res. 2011, 217, 10-15. [CrossRef]

59. Javed, H.; Khan, M.M.; Ahmad, A.; Vaibhav, K.; Ahmad, M.E.; Khan, A.; Ashafaq, M.; Islam, F.; Siddiqui, M.S.; Safhi, M.M.; et al. Rutin prevents cognitive impairments by ameliorating oxidative stress and neuroinflammation in rat model of sporadic dementia of Alzheimer type. Neuroscience 2012, 210, 340-352. [CrossRef]

60. Sadeghnia, H.R.; Yousefsani, B.S.; Rashidfar, M.; Boroushaki, M.T.; Asadpour, E.; Ghorbani, A. Protective effect of rutin on hexachlorobutadiene-induced nephrotoxicity. Renal Fail. 2013, 35, 1151-1155. [CrossRef]

61. Ghorbani, A. Mechanisms of antidiabetic effects of flavonoid rutin. Biomed. Pharmacother. 2017, 96, 305-312. [CrossRef]

62. Wu, Z.; Xie, Y.; Morrison, R.F.; Bucher, N.L.; Farmer, S.R. PPARgamma induces the insulin-dependent glucose transporter GLUT4 in the absence of C/EBPalpha during the conversion of 3T3 fibroblasts into adipocytes. J. Clin. Investig. 1998, 101, 22-32. [CrossRef]

63. Fu, Y.; Luo, N.; Klein, R.L.; Garvey, W.T. Adiponectin promotes adipocyte differentiation, insulin sensitivity, and lipid accumulation. J. Lipid Res. 2005, 46, 1369-1379. [CrossRef] [PubMed]

64. Khan, A.; Pessin, J. Insulin regulation of glucose uptake: A complex interplay of intracellular signalling pathways. Diabetologia 2002, 45, 1475-1483.

65. Huang, S.; Czech, M.P. The GLUT4 Glucose Transporter. Cell Metab. 2007, 5, 237-252. [CrossRef] [PubMed]

66. Kuo, Y.-H.; Lin, C.-H.; Shih, C.-C. Caffeamide 36-13 Regulates the Antidiabetic and Hypolipidemic Signs of High-Fat-Fed Mice on Glucose Transporter 4, AMPK Phosphorylation, and Regulated Hepatic Glucose Production. Evid. Based Complement. Alternat. Med. 2014, 2014, 1-12. [CrossRef] [PubMed] 
67. Grisouard, J.; Timper, K.; Radimerski, T.M.; Frey, D.M.; Peterli, R.; Kola, B.; Korbonits, M.; Herrmann, P.; Krähenbühl, S.; Zulewski, H.; et al. Mechanisms of metformin action on glucose transport and metabolism in human adipocytes. Biochem. Pharmacol. 2010, 80, 1736-1745. [CrossRef] [PubMed]

68. Liu, J.; Ye, C.; Liu, W.; Zhao, W.; Zhang, Y.-J.; Zhang, H.; Ying, H. AICAR enhances insulin signaling via downregulation of miR-29. Can. J. Physiol. Pharmacol. 2016, 94, 199-205. [CrossRef]

69. Gaidhu, M.P.; Ceddia, R.B. The Role of Adenosine Monophosphate Kinase in Remodeling White Adipose Tissue Metabolism. Exerc. Sport Sci. Rev. 2011, 39, 102-108. [CrossRef] [PubMed]

70. Cai, E.P.; Lin, J.K. Epigallocatechin gallate (EGCG) and rutin suppress the glucotoxicity through activating IRS2 and AMPK signaling in rat pancreatic beta cells. J. Agric. Food Chem. 2009, 57, 9817-9827. [CrossRef]

71. Yeo, C.-R.; Yang, C.; Wong, T.-Y.; Popovich, D.G. A Quantified Ginseng (Panax ginseng C.A. Meyer) Extract Influences Lipid Acquisition and Increases Adiponectin Expression in 3T3-L1 Cells. Molecules 2011, 16, 477-492. [CrossRef]

72. Avram, M.M.; Avram, A.S.; James, W.D. Subcutaneous fat in normal and diseased states: 3. Adipogenesis: From stem cell to fat cell. J. Am. Acad. Dermatol. 2007, 56, 472-492. [CrossRef]

73. Camp, H.S.; Ren, D.; Leff, T. Adipogenesis and fat-cell function in obesity and diabetes. Trends. Mol. Med. 2002, 8, 442-447. [CrossRef]

74. White, U.A.; Stephens, J.M. Transcriptional factors that promote formation of white adipose tissue. Mol. Cell. Endocrinol. 2010, 318, 10-14. [CrossRef] [PubMed]

75. Tzeng, T.-F.; Chang, C.J.; Liu, I.-M. 6-Gingerol Inhibits Rosiglitazone-Induced Adipogenesis in 3T3-L1 Adipocytes. Phytother. Res. 2014, 28, 187-192. [CrossRef] [PubMed] 